\title{
Molecular characterization of Tunisian families with abetalipoproteinemia and identification of a novel mutation in MTTP gene
}

Mohamed Najah ${ }^{1 *}$, Sarraj Mohamed Youssef ${ }^{1}$, Hrira Mohamed Yahia ${ }^{2}$, Slimani Afef ${ }^{1}$, Jelassi Awatef ${ }^{1}$, Hammami Saber ${ }^{3}$, Najjar Mohamed Fadhel ${ }^{4}$, Agnès Sassolas ${ }^{5}$ and Slimane Mohamed Naceur ${ }^{1 *}$

\begin{abstract}
Background: Abetalipoproteinemia (ABL; OMIM 200100) is a rare monogenic disorder of lipid metabolism characterized by reduced plasma levels of total cholesterol (TC), low density lipoprotein-cholesterol (LDL-C) and almost complete absence of apolipoprotein B (apoB). ABL results from genetic deficiency in microsomal triglyceride transfer protein (MTP; OMIM 157147). In the present study we investigated two unrelated Tunisian patients, born from consanguineous marriages, with severe deficiency of plasma low-density lipoprotein (LDL) and apo B.

Methods: Intestinal biopsies were performed and The MTTP gene was amplified by Polymerase chain reaction then directly sequenced in patients presenting chronic diarrhea and retarded growth.

Results: First proband was homozygous for a novel nucleotide deletion (c. $2611 \mathrm{delC}$ ) involving the exon 18 of MTTP gene predicted to cause a non functional protein of 898 amino acids (p.H871I fsX29). Second proband was homozygous for a nonsense mutation in exon 8 (c.923 G > A) predicted to cause a truncated protein of 307 amino acids (p.W308X), previously reported in ABL patients.
\end{abstract}

Conclusions: We discovered a novel mutation in MTTP gene and we confirmed the diagnosis of abetalipoproteinemia in new Tunisian families.

Virtual slides: The virtual slide(s) for this article can be found here: http://www.diagnosticpathology.diagnomx.eu/ vs/8134027928652779.

Keywords: Abetalipoproteinemia, Tunisian children, Mutations, MTTP gene

\section{Background}

$\mathrm{ABL}$ is a rare autosomal recessive metabolic disorder characterized by very low levels of total cholesterol (TC), low density lipoprotein- cholesterol (LDL-C) and almost the complete absence of apolipoprotein B-containing lipoproteins [1]. Patients with ABL have severe fat malabsorption, retarded growth, lipid accumulation in hepatocytes and enterocytes, and peripheral blood acanthocytosis essentially in early childhood, and later develop a retinitis pigmentosa and neuropathy due to fat soluble vitamins deficiency specifically vitamin E. Other manifestations of ABL include also hepatic steatosis and hepatomegaly [2].

\footnotetext{
*Correspondence: najahbs@yahoo.fr; Naceur. Slimene@fmm.rnu.tn ${ }^{1}$ Research Unit: UR 12 ES09 Dyslipidemia and Atherogenesis, Faculty of Medicine, Monastir, Tunisia

Full list of author information is available at the end of the article
}

Heterozygotes ABL patients usually have normal plasma levels of TC and LDL-C [3].

$\mathrm{ABL}$ is due to mutations in the MTTP gene encoding for the microsomal triglyceride transfer protein (MTP) a protein of $97-\mathrm{kDa}$, containing 894 amino acids, that forms an heterodimer with the protein disulfide isomerase (PDI). MTP protein is essentially expressed in endoplasmic reticulum of hepatocytes and enterocytes and plays a key role on the assembly and secretion of apo B-containing lipoproteins in both liver and intestine [4-7].

The MTP molecule consists of three structural domains: $\mathrm{N}$-terminal $\beta$-barrel (residues 22-297), $\alpha$-helical (residues 298-603) and C-terminal domains (residues 604-894). The $\mathrm{N}$-terminal $\beta$-barrel domain mediates the interaction with the $\mathrm{N}$ terminus of apo $\mathrm{B}$; the middle $\alpha$-helical domain mediates the interaction with both PDI and apo B; and the

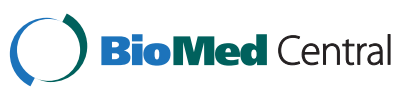


C-terminal mediates the lipid-binding and transfer catalytic activity of MTP $[6,8,9]$.

To our knowledge, more than 50 patients with ABL were described in the literature. Most of MTTP gene mutations result in truncated proteins [10,11]. Missense mutations have been also reported in atypical cases of $\mathrm{ABL}$ and were associated with a milder form of the disease [12-14].

The aim of the present study was to characterize two unrelated Tunisian patients with the clinical manifestations and plasma lipid profile consistant with ABL. They were found to be homozygous for two mutations respectively, one of which is new in MTTP gene.

\section{Methods}

\section{Clinical data and recruitment of family members}

All subjects investigated are living in Tunisia and are of Tunisian ancestry. Informed consent was obtained from all adult subjects, and in the case of children, from their parents. The study was approved by the Ethics Committees of each participating institution. Family members (parents and their child) of the patients were asked to take part in the study.

\section{Patient II.1 (Family E)}

The proband (subject II.1 in Figure 1) is a one year-old girl, born from a consanguineous marriage. She was referred to the hospital at the age of 10 months for the presence of hypotrophy and retarded growth. First observation showed that patient presented a steatorrhea (11.54 g/24 hours) with episodes of diarrhea. On physical examination, her weight was $3700 \mathrm{~g}$ and she had a height standard deviation score of -4.8 SDS.

Exploration showed that levels of ASAT and ALAT were $169 \mathrm{IU} / \mathrm{L}$ (normal values $<38 \mathrm{IU} / \mathrm{L}$ ) and $214 \mathrm{IU} / \mathrm{L}$ (normal values $<41 \mathrm{IU} / \mathrm{L}$ ) respectively. A normal level of gammaglutaryl transferase: 16 IU/L and an elevation

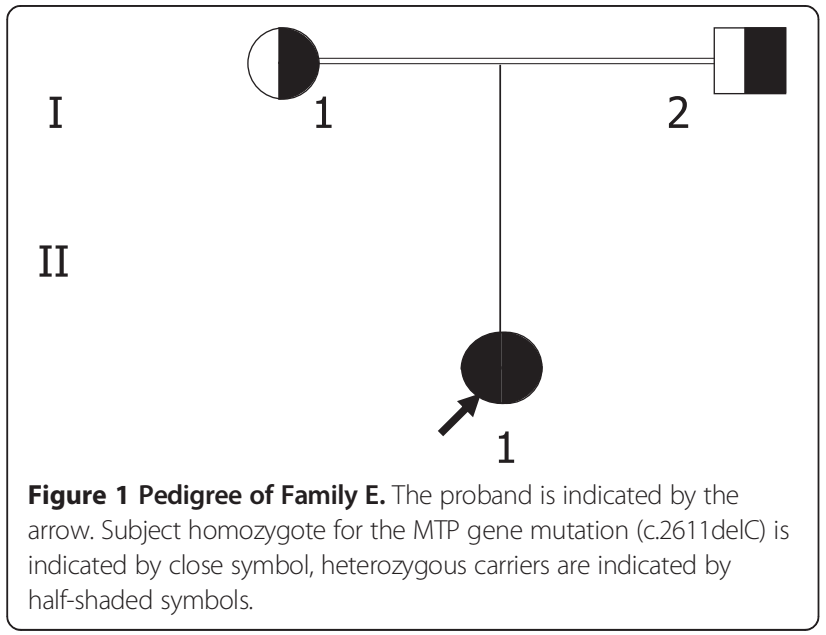

of alcaline phosphatase (179 IU/L) (normal values 40$150 \mathrm{IU} / \mathrm{L}$ ) were observed. Calcemia and total protein were normal. Acanthocytosis was revealed on peripheral blood smear. The lipid levels at the time of hospitalization were CT: $1.3 \mathrm{mmol} / \mathrm{l}$, TG: $0.35 \mathrm{mmol} / \mathrm{l}$ and HDL-C: 0.9 $\mathrm{mmol} / \mathrm{l}$. Values of vitamins were $430 \mu \mathrm{g} / \mathrm{l}$ for vitamine A (normal values 444-945 $\mu \mathrm{g} / \mathrm{l})$, vitamine $\mathrm{E}(<1 \mu \mathrm{mol} / \mathrm{l})$ was undetectable (normal values $16-35 \mu \mathrm{mol} / \mathrm{l}$ ). The patient was treated by restricting dietary fat and by supplementation of fat soluble vitamin A 25000 IU daily and vitamin E $500 \mathrm{mg}$ daily during three months. No neurological or ophthalmic abnormalities were found.

\section{Patient II.2 (Family D)}

The proband (subject II.2 in Figure 2) is a 20 year-old boy born from a consanguineous marriage. He suffered from a long history of sever hypobetalipoproteinemia. Clinical data showed that he was first referred to the hospital at the age of 5 months for the exploration of a prolonged diarrhea and retarded growth. Followed by oral and venous rehydration, antibiotherapy and a diet excluding proteins of cow's milk; the evolution of the child was fluctuating. He left the hospital without any retained diagnosis; a low -fat diet was prescribed. The patient was present for a second examination at 4 years of age with chronic diarrhea and postprandial vomiting and retarded growth (-3DS). At this time a difficulty of the vision (twilight and night) and a disorder of walking were first observed. Anemia ( $\mathrm{Hb} 8.9 \mathrm{mg} / \mathrm{dl})$ and vitamine $\mathrm{E}$ deficiency (Vit $\mathrm{E}<1 \mu \mathrm{mol} / \mathrm{l}$ ) (normal values 16-35 $\mu \mathrm{mol} / \mathrm{l}$ ) were noted. Acanthocytosis was revealed on peripheral blood smear. At this age the diagnosis of familial hypobetalipoproteinemia was taken upon the low plasmatic lipids levels (CT: $1.28 \mathrm{mmol} / \mathrm{l}$; TG: $0.31 \mathrm{mmol} / \mathrm{l}$; apoB and LDL-C: undetectable). Ophthalmic examinations showed a peripheral hyperpigmentation of the retina. Neurological examinations revealed the presence of cerebellar syndrome

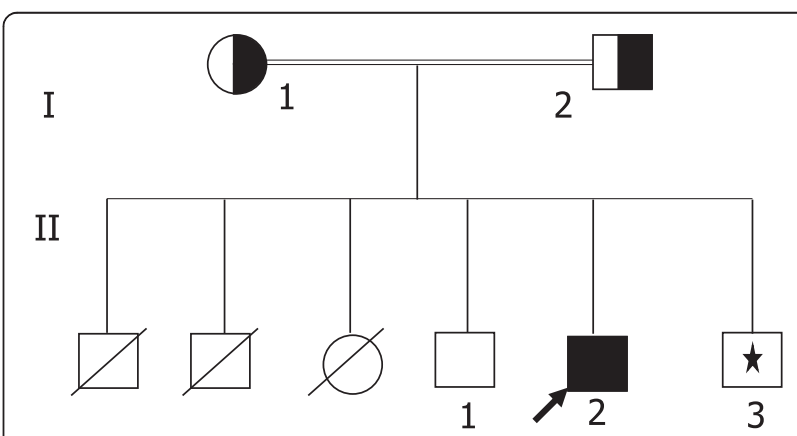

Figure 2 Pedigree of Family D. The proband is indicated by the arrow. Subject homozygote for the MTP gene mutation (c.923 G>A) is indicated by close symbol; heterozygous carriers are indicated by half-shaded symbols. Family member not available for the study is indicated by an asterisk. 
and reduction in the osteotendinous reflexes. The patient was treated, during one year, by oral vitamin A 25000 IU daily, vitamin E $800 \mathrm{mg}$ daily, and vitamin K $40 \mathrm{mg}$ every 15 days, the postprandial vomiting, walk and osteotendinous reflexes were normalized with a growth amelioration (-1DS). The other observations were not changed except the normalization of hemoglobin. Then, $5 \mathrm{mg}$ daily of vitamin $\mathrm{K}$ were changed in his treatment and he was followed yearly until the age of 12 years. His health remained stable (Lipid values during follow-up were not documented in the clinical database). At age 20, he was hospitalized again, Neurological and ophthalmic examinations revealed a complete absence of osteo-tendinous reflexes, sensitive axonal neuropathy and pigmentary retinal degeneration. The hepatic ultrasound examination showed the presence of fatty liver. Plasma triglycerides and cholesterol were decreased, with undetectable LDL-C, ApoB and Vitamin E (Vit E $<1 \mu \mathrm{mol} / \mathrm{l}$ ). As the treatment was stopped for a long period the initial doses of vitamins were prescribed associated with a restricting dietary fat.

\section{Lipid and lipoprotein analysis}

For all family members plasma lipid values were obtained after an overnight fast. Plasma TC, TG and HDL-C concentrations were measured by a standard method using the Synchrom CX7 clinical system (Beckman, Fullerton, CA, USA). LDL-C concentration was calculated using the Friedewald's Formula. ApoA-I, apoB were measured by immunonephelometry using the IMMAGE immunochemistry system (Beckman, Fullerton, CA, USA).

\section{Intestinal biopsy}

Following a period of 12 hours fasting, duodenal biopsies were obtained from probands. Tissues were fixed in $10 \%$ buffered formalin and embedded in paraffin for routine histology stained with hematoxylin and eosin.

\section{Molecular analysis}

Genomic DNA was isolated from whole blood EDTA samples using the salting-out method [15]. For the family E patient, MTTP gene was amplified and directly sequenced as previously described [16]. In the case of family $\mathrm{D}$, The promoter and all exons as well as flanking intronic sequences of the MTTP gene were amplified by polymerase chain reaction (PCR) as previously described [10], then PCR products were sequenced using BigDyeDeoxy terminator cycle sequencing reagents according to the manufacturer's instructions and templates were sequenced on an automated ABI-PRISM 310 Genetic Analyzer (Applied Biosystems). Further, the MTTP mutations found in the probands were screened by direct sequencing in all family members available for study.

\section{Mutation nomenclature}

MTTP mutations were designated according to the Human Genome Variation Society. Nucleotide numbers are derived from MTTP cDNA sequence (GenBank accession no. NM_000253.2), considering the A of first ATG translation initiation codon as nucleotide +1 . Amino acid sequence MTP protein are described according to the National Center for Biotechnology Information reference sequence (MTP, GenBank accession no. NP_000244.2).

\section{Results}

The first proband of family E (subject II.1 in Figure 1 and Table 1) had extremely low plasma lipids with undetectable LDL-C and apoB (Table 1). As no data are available for the Tunisian population [10-34], the lipid values were compared to the 95th percentile of the levels found in the European populations suggesting a condition of hypobetalipoproteinemia [3]. The duodenal biopsy showed the presence of enterocyte vacuolization specifically at the tip of the villi suggestive of fat accumulation (Figure 3). Proband's parents (Table 1) had a normal plasma lipid profile, strongly suggesting that the child might have ABL. The analysis of MTTP gene revealed that the proband was homozygous for a novel deletion in the exon 18 (c. 2611delC) expected to cause a frameshift in the mRNA by changing the sequence of the 23 last amino acids on C-terminal domain (residues 604-894) and adding 3 amino acids. The translation product of this abnormal mRNA is an MTP protein containing 898 amino acids (p.H871I fsX29) instead of 894 amino acids of the normal protein (Additional file 1). Proband's parents were heterozygous.

The second proband of family D (subject II.2, in Figure 2 and Table 2) had extremely low plasma lipids. Plasma LDL-C and apoB were undetectable. The duodenal biopsy showed the presence of enterocyte vacuolization suggesting the presence of lipid droplets (Figure 4). Proband's father (subject I.2 in Table 2) had a normal plasma lipid profile. Although the proband's mother (subject I.1 in Table 2) had plasma levels of TC, LDL-C and apoB below the 95th percentile of the levels found in the European populations it was not possible to define to what extent the values observed in proband's mother diverge from the mean in our population. The proband's brother (subject II.1 in Table 2) had also low plasma lipids.

In view of the lipid profile of proband's parents and because we already described a Tunisian ABL family whith hypocholesteroleima in one of his parents [10], we assumed that the proband might be affected by ABL. The sequence of MTTP gene showed that the proband was homozygous for (c.923 G > A) mutation in exon 8 . The result is a truncated protein of 307 amino acids, as opposed to the 894 amino acids, devoid of function. 
Table 1 Plasma lipid and apolipoprotein levels in Family E

\begin{tabular}{|c|c|c|c|c|c|c|c|c|}
\hline Subject & Age (years) & & TC & TG & LDL-C & HDL-C & ApoB & ApoA-I \\
\hline & & & \multicolumn{4}{|c|}{$\mathrm{Mmol} / \mathrm{I}$} & \multicolumn{2}{|c|}{$\mathrm{mg} / \mathrm{dl}$} \\
\hline I.1 & 33 & & 4.39 & 1.47 & 2.6 & 1.16 & 70 & 178 \\
\hline 1.2 & 38 & & 5.46 & 1.09 & 3.08 & 1.63 & 87 & 191 \\
\hline \multirow[t]{2}{*}{$\| .1$} & 1 & & 0.58 & 0.14 & und & 0.37 & und & 49 \\
\hline & & Normal range & $3.9-6.7$ & $0.68-1.7$ & $2.5-4.4$ & $>1.2$ & $30-95$ & $90-200$ \\
\hline
\end{tabular}

$T C$, total cholesterol; $T G$, triglyceride; $L D L-C$, low density lipoprotein-cholesterol; $H D L-C$, high density lipoprotein-cholesterol; $A p o$, apolipoprotein; und, undetectable.

Proband's parents were heterozygous and his brother (subject II.1 in Figure 2) present on this study was normal.

\section{Discussion}

$\mathrm{ABL}$ is a rare autosomal recessive metabolic disorder characterized by complete absence of plasma apo B-containing lipoproteins that results from mutations in MTTP gene. Patients with ABL may develop severe neurological manifestations if they are not treated $[2,17,18]$.

Abetalipoproteinemia is characterized, in term of clinical manifestations, with homozygous Familial Hypobetalipoproteinmia (FHBL; OMIM 107730) and Chylomicron Retention disease (CMRD; OMIM 246700), two other monogenic disorders of lipid metabolism by manifestations such as steatorrhea, retarded growth and chronic diarrhea associated with hypocholesterolemia. Under these conditions the use of the lipid profile of proband's parents is essential to lead and facilitate the molecular diagnosis of these metabolic disorders: familial hypobetalipoproteinemia is a rare autosomal codominant disorder of lipoprotein metabolism, it results that both

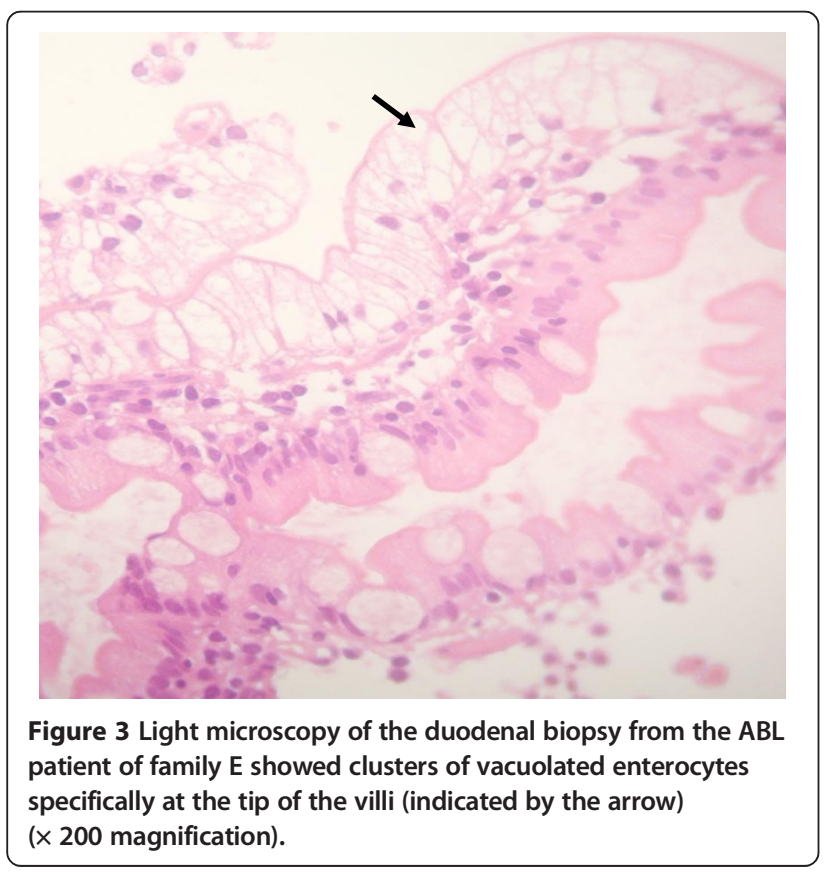

parents are expected to have plasma levels of TC, LDL-C and apoB lower than those found in normal subjects $[3,19]$. In $A B L$ and CMRD with an autosomal recessive transmission, obligate heterozygotes have almost normal plasma lipoprotein profiles, with some exception and usually normal level of TG in patients homozygous for CMRD $[2,20]$.

In this paper, we characterize two new Tunisian families with a severe form of hypobetalipoproteinemia. The common clinical features shared by patients were diarrhea, failure to thrive, acanthocytosis and lipid accumulation in enterocytes. The diagnosis of ABL was confirmed in these families and patients were found to be homozygotes for two mutations; one of them, which involves the exon 18, is novel on MTTP gene.

In the case of families $\mathrm{E}$ and $\mathrm{D}$, probands presented with a similar lipid profile and very low plasma levels of TC, TG and undetectable LDL-C and apoB. In family E, the lipid values of proband's parents, were within the normal range (Table. 1). The MTTP gene sequencing showed that proband of family $\mathrm{E}$ was homozygous for a novel mutation on MTTP gene (c.2611delC), predicted to result in a protein of 898 amino acids. It is well known that C-terminal domain (residues 604-894) mediate the lipid binding and the transfer catalytic activity of MTP $[8,27]$. The abnormal protein is expected to be non functional, since the sequence of the $\mathrm{C}$-terminal domain was changed. It was demonstrated that $\mathrm{C}$-terminal domain is preferentially conserved amongst vertebrates suggesting that this region might be critical for the triacylglycerol transfer activity associated with MTP [28]. The truncated MTP protein resulting from the mutation (p.G865X), involving the exon 18, was suggested to interfere with the association between the $97 \mathrm{kD}$ subunit of MTP and PDI $[24,29]$. Other MTP truncations devoid of the C-terminal domain $[25,30]$ or missense mutations located in this domain [12,13] have been described in patients with $A B L$ highlighting the functional role of the C-terminal domain.

In family $\mathrm{D}$, we found the third Tunisian patient with (c.923 G > A) mutation in homozygous state. This mutation was found for the first time in two Tunisian affected brothers (unrelated to the patient in the present study) 
Table 2 Plasma lipid and apolipoprotein levels in Family D

\begin{tabular}{|c|c|c|c|c|c|c|c|c|}
\hline Subject & Age (years) & & $\mathrm{TC}$ & TG & LDL-C & HDL-C & ApoB & ApoA-I \\
\hline & & & \multicolumn{4}{|c|}{$\mathrm{Mmol} / \mathrm{I}$} & \multicolumn{2}{|c|}{$\mathrm{mg} / \mathrm{dl}$} \\
\hline 1.1 & 55 & & 2.9 & 0.7 & 1.4 & 1.2 & 68 & 149 \\
\hline 1.2 & 75 & & 4.1 & 0.87 & 2.11 & 1.59 & 94 & 135 \\
\hline$\| .1$ & 15 & & 2.3 & 0.79 & 0.59 & 1.42 & 35 & 100 \\
\hline \multirow[t]{2}{*}{$\| .2$} & 20 & & 1.3 & 0.35 & Und & 0.9 & und & 35 \\
\hline & & Normal range & $3.9-6.7$ & $0.68-1.7$ & $2.5-4.4$ & $>1.2$ & $30-95$ & $90-200$ \\
\hline
\end{tabular}

$T C$, total cholesterol; $T G$, triglyceride; $L D L-C$, low density lipoprotein-cholesterol; $H D L-C$, high density lipoprotein-cholesterol; Apo, apolipoprotein; und, undetectable.

and it leads to a truncated MTP protein of 307 amino acids (p.W308X) devoid of function [10]. The proband's parents were heterozygous and his brother was normal. Proband's mother (subject I.1 in Table 2) had low plasma lipid levels suggestive of hypobetalipoproteinemia, even though, the lipid plasma values within the lower limit or low values of TC and apoB were observed in heterozygous subjects for the same mutation (c.923 G > A) in a previous study [10]. This is not surprising as heterozygous $A B L$ (specifically one of the parents) were reported with low plasma TC, LDL-C and apoB in other single families [21-23], and the possibility that human MTP deficiency is inherited in a codominant manner had been also suggested in heterozygous of MTP knockout mice with reduced plasma apoB levels [35].

The proband's brother (subject II.1 in Table 2), with normal genotype, had low levels of $\mathrm{TC}$ and apoB although he was healthy and had no history of malabsorption or failure to thrive. The biochimical phenotype of family D strongly confirms the existence of a Tunisian specificity associated with monogenic dyslipidemias, since we recently showed a low level of plasma lipids in heterozygous for CMRD [36] and normal or moderate levels of CT and LDL-C in heterozygous familial hypercholestetolemia (FH) [37]. The lipid profile of proband's brother (subject II.1 in Table 2) can be attributed either to the low content of fats in the mediterranean diet which characterize Tunisian population [38] or to the coexistence of other cholesterol-lowering gene(s) associated with hypobetalipoproteinemia in this family. In addition, it has been shown that some polymorphisms in genes related to the metabolism of lipoproteins, have been associated with lipid levels in Tunisian patients affected by other diseases like cardiovascular pathologies [39]. This reflects, in part, the genetic background heterogeneity of the Tunisian population demonstrated in other genetic disorders [40].

Many mutations in MTTP gene described in literature as cause of $\mathrm{ABL}$ were private and related to single families. There was an exception with (p.G865X) mutation which was found in ABL patients from USA and Canada and was also reported in the Ashkenazi Jewish population with a high prevalence and a founder effect $[12,25]$. The (419insA) mutation was also associated with ABL in patients of European ancestry $[13,26]$. In Tunisian population, four mutations in MTTP gene (c.923 G>A, c.619-3 T> G, c.1236+2 T> G and c. $2342+1 \mathrm{G}>\mathrm{A}$ ) have been reported as cause of ABL in four single families $[10,36]$. In this study, the diagnosis of the mutation (c.923 G>A) in a new Tunisian family is suggestive of a high prevalence of the mutant allele in heterozygote state.

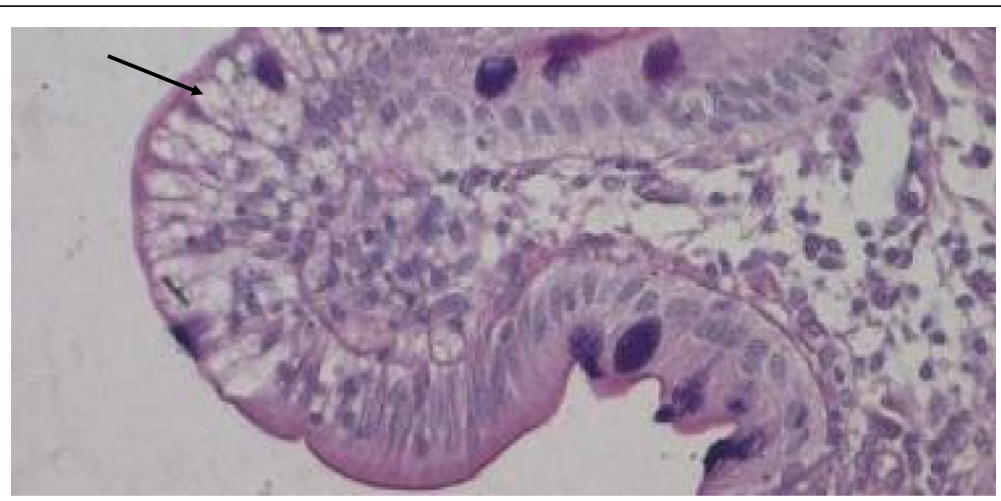

Figure 4 Light microscopy of the duodenal biopsy from the ABL patient of family $D$ showed clusters of vacuolated enterocytes specifically at the tip of the villi (indicated by the arrow) ( $\times 200$ magnification). 
Although, the clinical data available were rather incomplete (especially hepatic exploration), our patients presented the typical hematologic and gastrointestinal features of $\mathrm{ABL}$ such as acanthocytosis, diarrhea during infancy and malabsorption with mild anemia (proband II.2 of family D in this paper) which was reported in some cases of $\mathrm{ABL}[10,21]$. Usually neurological manifestations begin later in life in ABL patients, especially those who have not been given a supplementation of vitamin E [31]. Later supplementation of fat soluble vitamins in patient II.2 (family D) allowed the osteotendinous reflexes reduction. Previous studies showed that early therapy with vitamin E, before the age of 16 months prevents neurologic dysfunction [32,33]. Elevated Transaminases serum of the proband II.1 (family E) is suggestive of hepatic steatosis which is needed to be confirmed by liver biopsy in this patient. It was reported that hepatic manifestations in $\mathrm{ABL}$ cases included hepatomegaly due to hepatic steatosis in association with elevated transaminases [34,41]. The absence of neurological and opthalmological manifestations in patient II.1 (family E) is consistant with the observation that the diagnosis of ABL should be made in children with malabsorption, acanthocytosis and hypocholesterolemia. Indeed a low-fat diet and fat-soluble vitamins supplementation can prevent later complications [17].

\section{Conclusion}

Five ABL patients have been reported in Tunisian population $[10,36]$. In this work we characterize two other unrelated patients affected by this metabolic disorder and we identify a novel mutation in MTTP gene leading to a non functional protein. Although it is a rare disease, abetalipoproteinemia seems to have a high prevalence in Tunisia. Knowledge of MTTP gene mutations allows us to set up a sensitive and specific use of genetic testing for screening carriers in other families.

\section{Additional file}

Additional file 1: Analysis of the MTTP gene. The chromatogram show the partial sequence of exon 18 in the proband II.1 (family E). In above, the normal MTTP gene sequence (reference NM_000253). In the below, mutant sequence show the homozygous state of the novel nucleotide deletion (c. $2611 \mathrm{delC}$ ) and the frameshift in the mRNA. The predicted translation product of the mutant MTTP gene is a non functional protein of 898 amino acids (p.H871I fsX29) lacking the last 23 functional amino-acids.

\section{Abbreviations}

ABL: Abetalipoproteinemia; ApoA-l: Apolipoprotein A-l; ApoB: Apolipoprotein B; CM: Chylomicrons; CMRD: Chylomicron Retention Disease; FHBL: Familial Hypobetalipoproteinemia; HDL-C: High density lipoprotein-cholesterol; LDL-C: Low density lipoprotein-cholesterol; mRNA: Messenger RNA; MTP: Microsomal triglyceride transfer protein; MTTP: Microsomal triglyceride transfer protein large subunit gene; PCR: Polymerase chain reaction; PDI: Protein disulfide isomerase; TC: Total cholesterol; 1TG: Triglyceride.

\section{Competing interests}

The authors declare that they have no competing interests.

\section{Authors' contributions}

NM wrote the manuscript. SMY and HMY participated in data analysis. AS and SMN revised the manuscript and save final approval of the version to be published. All authors read and approved the final manuscript.

\section{Acknowledgements}

We are indebted to all family members for their cooperation. This work was supported by grants from the Direction Générale de la Recherche Scientifique et Technique (Tunisia). We thank Prof Rouis M. from I'Université Pierre et Marie Curie, Paris, (France) for his assistance and all member team of Laboratory of Biochemistry and Toxicology of the University Hospital of Monastir.

\section{Author details}

${ }^{1}$ Research Unit: UR 12ES09 Dyslipidemia and Atherogenesis, Faculty of Medicine, Monastir, Tunisia. ${ }^{2}$ Research Unit 07/UR/06, Faculty of Pharmacy, Monastir, Tunisia. ${ }^{3}$ Faculty of Medicine, Monastir, Pediatric Service, University Hospital of Monastir, Monastir, Tunisia. ${ }^{4}$ Laboratory of Biochemistry and Toxicology of the University Hospital of Monastir, Monastir, Tunisia. ${ }^{5}$ NSERM U1060 CarMeN, University of Lyon, Lyon, France.

Received: 6 December 2012 Accepted: 10 January 2013

Published: 4 April 2013

\section{References}

1. Kane J, Havel R: Disorders of the biogenesis and secretion of lipo-proteins containing the $\mathrm{B}$ apolipoproteins. In The metabolic and molecular bases of inherited disease. Edited by Scriver C, Beaudet A, Sly W, Valle D. New York: McGraw-Hill; 2001:2717-2752.

2. Zamel R, Khan R, Pollex RL, Hegele RA: Abetalipoproteinemia: two case reports and a literature review. Orphanet J Rare Dis 2008, 3:19.

3. Tarugi $P$, Averna M, Di Leo E, Cefalù AB, Noto D, Magnolo L, Cattin L, Bertolini S, Calandra S: Molecular diagnosis of hypobetalipoproteinemia: an ENID review. Atherosclerosis 2007, 195:19-27.

4. Wetterau JR, Aggerbeck LP, Bouma ME, Eisenberg C, Munck A, Hermier M, Schmitz J, Gay G, Rader DJ, Gregg RE: Absence of microsomal triglyceride transfer protein in individuals with abetalipoproteinemia. Science 1992, 258:999-1001.

5. Shoulders CC, Brett DJ, Bayliss JD, Narcisi TM, Jarmuz A, Grantham TT, Leoni PR, Bhattacharya S, Pease RJ, Cul-len PM, Sassoon L, ByWeld PGH, Purkiss P, Scott J: Abetalipoproteinemia is caused by defects of the gene encoding the $97 \mathrm{kDa}$ subunit of a microsomal triglyceride transfer protein. Hum Mol Genet 1993, 2:2109-2116.

6. Hussain MM, Shi J, Dreizen P: Microsomal triglyceride transfer protein and its role in ApoB-lipoprotein assembly. J Lipid Res 2003, 44:22-32.

7. Hussain MM, Rava P, Walsh M, Rana M, lqbal J: Multiple functions of microsomal triglyceride transfer protein. Nutr Metab 2012, 9:14.

8. Mann CJ, Anderson TA, Read J, Chester SA, Harrison GB, Kochl S, Ritchie PJ, Bradbury P, Hussain FS, Amey J, Vanloo B, Rosseneu M, Infante R, Hancock JM, Levitt DG, Banaszak LJ, Scott J, Shoulders CC: The structure of vitellogenin provides a molecular model for the assembly and secretion of atherogenicc lipoproteins. J Mol Biol 1999, 285:391-408.

9. Bradbury P, Mann CJ, Kochl S, Anderson TA, Chester SA, Hancock JM, Ritchie PJ, Amey J, Harrison GB, Levitt DG, Banaszak LJ, Scott J, Shoulders CC: A common binding site on the microsomal triglyceride transfer protein for apolipoprotein B and protein disulfide isomerase. J Biol Chem 1999, 274:3159-3164.

10. Najah M, Di Leo E, Jelassi A, Magnolo L, Imene J, Pinotti E, Bahari M, Barsaoui S, Brini I, Fekih M, Slimane MN, Tarugi P: Identification of patients with abetalipoproteinemia and homozygous familial hypobetalipoproteinemia in Tunisia. Clin Chim Acta 2009, 401:51-56.

11. Pons V, Rolland C, Nauze M, Danjoux M, Gaibelet G, Durandy A, Sassolas A, Lévy E, Tercé F, Collet X, Mas E: A severe form of abetalipoproteinemia caused by new splicing mutations of microsomal triglyceride transfer protein (MTTP). Hum Mutat 2011, 32:751-759.

12. Wang J, Hegele RA: Microsomal triglyceride transfer protein (MTP) gene mutations in Canadian subjects with abetalipoproteinemia. Hum Mutat 2000, 15:294-295. 
13. Ohashi K, Ishibashi S, Osuga J, Tozawa R, Harada K, Yahagi N, Shio-noiri F, lizuka Y, Tamura Y, Nagai R, Illingworth DR, Gotoda T, Yamada N: Novel mutations in the microsomal triglyceride transfer protein gene causing abetalipoproteinemia. J Lipid Res 2000, 41:1199-1204.

14. Al-Shali K, Wang J, Rosen F, Hegele RA: lleal adenocarcinoma in a mild phenotype of abetalipoproteinemia. Clin Genet 2003, 63:135-138.

15. Miller SA, Dykes DD, Polesky HF: A simple salting out procedure for extraction DNA from human nucleated cells. Nucleic Acid Res 1988, 16:1215.

16. Di Filippo $M$, Créhalet $H$, Samson-Bouma ME, Bonnet V, Aggerbeck LP, Rabès JP, Gottrand F, Luc G, Bozon D, Sassolas A: Molecular and functional analysis of two new MTTP gene mutations in an atypical case of abetalipoproteinemia. J Lipid Res 2012, 53:548-555.

17. Tarugi P, Averna M: Hypobetalipoproteinemia: genetics, biochemistry, and clinical spectrum. Adv Clin Chem 2011, 54:81-107.

18. Berriot-Varoqueaux N, Aggerbeck LP, Samson-Bouma ME, Wetterau JR: The role of the microsomal triglyceride transfer protein in abetalipoproteinemia. Ann Rev Nutr 2000, 20:663-697.

19. Schonfeld G, Lin X, Yue P: Familial hypobetalipoproteinemia: genetics and metabolism. Cell Mol Life Sci 2005, 62:1372-1378.

20. Peretti N, Sassolas A, Roy CC, Deslanders C, Charcosset M, Castagnetti J, Pugnet-Chardon L, Moulin P, Labarge S, Bouthiller L, Lachaux A, Levy E: Guideline for the diagnosis and management of chylomicron retention disease based on a review of the literature and the experience of two centers. Orphanet J Rare Dis 2010, 5:24.

21. Di Leo E, Lancellotti S, Penacchioni JY, Cefalu AB, Averna M, Pisciotta L, Bertolini S, Calandra S, Gabelli C, Tarugi P: Mutations in MTP gene in abeta- and hypobeta-lipoproteinemia. Atherosclerosis 2005, 180:311-318.

22. Berthier MT, Couture $P$, Houde A, Paradis AM, Sammak A, Verner A, Depres JP, Gagne C, Gaudet D, Vohl MC: The c.419-420insA in the MTP gene is associated with abetalipopro- teinemia among French-Canadians. Mol Genet Metab 2004, 81:140-143.

23. Sani MN, Sabbaghian M, Mahjoob F, Cefalù AB, Averna MR, Rezaei N: Identification of a novel mutation of MTP gene in a patient with abetalipoproteinemia. Annals Hepathol 2011, 2:221-226.

24. Ricci B, Sharp D, O'Rourke E, Kienzle B, Blinderman L, Gor-don D, SmithMonroy C, Robinson G, Gregg RE, Rader DJ, Wetterau JR: A 30-amino acid truncation of the microsomal triglyceride transfer protein large subunit disrupts its interaction with protein disulfude-isomerase and causes abetalipoproteinemia. J Biol Chem 1995, 270:14281-14285.

25. Benayoun L, Granot E, Rizel L, Allon-Shalev S, Behar DM, Ben-Yosef T: Abetalipoproteinemia in Israel: evidence for a founder mutation in the Ashkenazi Jewish population and a contiguous gene deletion in an Arab patient. Mol Genet Metab 2007, 90:453-457.

26. Narcisi TM, Shoulders CC, Chester SA, Read J, Brett DJ, Harrison GB, Grantham TT, Fox MF, Povey S, de Bruin TW, Erkelens DW, Muller DPR, Llyod JK, Scott J: Mutations of the micro-somal triglyceride-transfer-protein gene in abetalipoproteinemia. Am J Hum Genet 1995, 57:1298-1310.

27. Read J, Anderson TA, Ritchie PJ, Vanloo B, Amey J, Levitt D, Rosseneu M, Scott J, Shoulders CC: A mechanism of membrane neutral lipid acquisition by the microsomal triglyceride transfer protein. J Biol Chem 2000, 275:30372-30377.

28. Rava P, Hussain MM: Acquisition of triacylglycerol transfer activity by microsomal triglyceride transfer protein during evolution. Biochemistry 2007, 46:12263-12274.

29. Rehberg EF, Samson-Bouma ME, Kienzle B, Blinderman L, Jamil H, Wetterau JR, Aggerbeck LP, Gordon DA: A novel abetalip-oproteinemia genotype. Identication of a missense mutation in the $97-\mathrm{kDa}$ subunit of the microsomal triglyceride transfer protein that prevents complex formation with protein disulfde isomerase. J Biol Chem 1996, 271:29945-29952.

30. Chardon L, Sassolas A, Dingeon B, Michel-Calemard L, Bovier-Lapierre M, Moulin $P$, Lachaux A: Identification of two novel mutations and long-term follow-up in abetalipoproteinemia: a report of four cases. Eur J Pediatr 2009, 168:983-989.

31. Hooper AJ, Van Bockxmeer FM, Burnett JR: Monogenic hypocholesterolaemic lipid disorders and apolipoprotein B metabolism. Crit Rev Clin Lab Sci 2005, 42:515-545.

32. Hegele RA, Angel A: Arrest of neuropathy and myopathy in abetalipoproteinemia with high-dose vitamin E therapy. Can Med Assoc J 1985, 132:41-44.

33. Muller DP, Lloyd JK, Wolff OH: The role of vitamin $\mathrm{E}$ in the treatment of the neurological features of abetalipoproteinaemia and other disorders of fat absorption. J Inherit Metab Dis 1985, 8(Suppl 1):88-92.

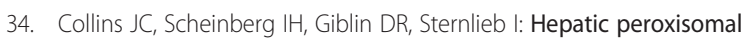
abnormalities in abetalipoproteinemia. Gastroenterology 1989, 97:766-770.

35. Raabe M, Flynn LM, Zlot CH, Wong JS, Véniant MM, Hamilton RL, Young SG: Knockout of the abetalipoproteinemia gene in mice: Reduced lipoprotein secretion in heterozygotes and embryonic lethality in homozygotes. Proc Natl Acad Sci USA 1999, 95:8686-8691.

36. Magnolo L, Najah M, Fancello T, Di Leo E, Pinotti E, Brini I, Gueddiche MN, Calandra S, Slimene MN, Tarugi P: Novel mutations in SAR1B and MTTP genes in Tunisian children with chylomicron retention disease and abetalipoproteinemia. Gene 2013, 512(1):28-34. in press.

37. Slimani A, Jelassi A, Jguirim I, Najah M, Rebhi L, Omezzine A, Maatouk F, Hamda KB, Kacem M, Rabès JP, Abifadel M, Boileau C, Rouis M, Slimane MN, Varret M: Effect of mutations in LDLR and PCSK9 genes on phenotypic variability in Tunisian familial hypercholesterolemia patients. Atherosclerosis 2012, 222:158-166.

38. Slimane MN, Pousse H, Maatoug F, Hammami M, BenFarhat MH: Phenotypic expression of familial hypercholesterolaemia in central and southern Tunisia. Atherosclerosis 1993, 104:153-158.

39. Hrira MY, Chkioua L, Slimani A, Chahed H, Mosbah H, Ben Khaldoun H, Ferchichi S, Addad F, Miled A: Hsp70-2 gene polymorphism: susceptibility implication in Tunisian patients with coronary artery disease. Diagn Pathol 2012, 7:88.

40. Hejer E, Nejla B, Asma J, Kaouther Z, Balkis M, Amel BAE, Emna G: Factor VIII haplotypes frequencies in Tunisian hemophiliacs A. Diagn Pathol 2011, 6:54.

41. Braegger CP, Belli DC, Mentha G, Steinmann B: Persistence of the intestinal defect in abetalipoproteinaemia after liver trans-plantation. Eur J Pediatr 1998, 157:576-578.

doi:10.1186/1746-1596-8-54

Cite this article as: Najah et al:: Molecular characterization of Tunisian families with abetalipoproteinemia and identification of a novel mutation in MTTP gene. Diagnostic Pathology 2013 8:54.

\section{Submit your next manuscript to BioMed Central and take full advantage of:}

- Convenient online submission

- Thorough peer review

- No space constraints or color figure charges

- Immediate publication on acceptance

- Inclusion in PubMed, CAS, Scopus and Google Scholar

- Research which is freely available for redistribution

Submit your manuscript at www.biomedcentral.com/submit
C BioMed Central 